\title{
Characteristics of Settlement Consolidation and Influencing Factors Analysis of Dredger Fill of Clay Soil Mixing Sand
}

\author{
Jihui-Ding ${ }^{1}$, Qi-Zhao ${ }^{2}$, Yafeng-Zhao ${ }^{3}$, Mengjia-Xiang ${ }^{4}$, Mingjiang-Wu ${ }^{5}$ \\ ${ }^{1,2,4}$ College of Civil Engineering Hebei University, Baoding, Hebei, China 071002 \\ ${ }^{3,5}$ CCCC Road \& Bridge Special Engineering Co Ltd, Wuhan, Hubei, China 430071
}

\begin{abstract}
Sedimentation column that the size of $100 \times 500 \mathrm{~mm}$ is used to study the relationship between the self weight settlement of cohesive soil and the initial sand-mud ratio and initial water content of dredger fill of clay soil mixing sand. Test results show that:(1) the consolidation time of dredger fill of clay soil mixing sand is mainly related to the size of the settlement column, compared with the initial water content, the influence of sand-mud ratio is not significant. The larger the size of the settlement column, the longer time of gravity consolidation will be completed, and the higher initial water content, the shorter time of consolidation. (2) The settlement curve of dredger fill of clay soil mixing sand is in accordance with the relation formula $S=A_{1} e^{-\frac{t}{t_{1}}}+A_{2} e^{-\frac{t}{t_{2}}}+S_{0}$.In the formula, $S_{0}$ is the steady settlement. The stability time of settlement consolidation can be deduced by this formula. Under the condition of the same water content, the consolidation settlement of dredger fill of clay soil mixing sand increases linearly with the sand-mud ratio, but the amplitude of the increase is not large; (3) the logarithmic curve of consolidation settlement is basically divided into three stages: The straight line segment, the upper concave line segment and the lower concave line segment. At first, the slope of the linear section increases gradually with the increase of the initial water content; The upper concave curve gradually decreases with the increase of water content, and when the initial water content reaches a certain value, the concave curve becomes a straight line; The lower concave curve section gradually changes to the curve type, then the slope of the settlement curve decreases and finally tends to the horizontal.
\end{abstract}

Keywords — clay soil mixing sand; self weight consolidation settlement; initial water content; initial sand-mud ratio.

\section{INTRODUCTION}

When the filling material flows out from the blowpipe, the filling material has the characteristics of sorting and partitioning. As the distance from the distance to the fill increases, the deposited soil particles gradually become coarser. Generally, dredger fill is characterized by obvious heterogeneity, high natural water content, poor water permeability, difficult drainage consolidation, high compressibility, low shear strength, thixotropy and rheological properties. The settlement consolidation characteristics of dredger fill are related to the design of yard volume, the selection of foundation treatment method and the effect of foundation treatment. Most of the existing scholars at home and abroad are pure silt soil, the simulation is the initial stage of dredging, the water content is very high, and the study of the self weight consolidation law of sand and clay soil mixing system is not very common. Stokes ${ }^{[1]}$ formula is the most classical particle settling velocity formula at present. In the aspect of settling velocity of mud water interface, IMAI ${ }^{[2-3]}$ considered that there are 3 stages of consolidation of cohesive sediment suspended sediment with high water content, namely, flocculation stage, settlement stage and consolidation stage. Liangtong $\mathrm{Zhan}^{[4]}$ used the $50 \mathrm{~cm}$ high sediment column (high $50 \mathrm{~cm}$, inner diameter $9 \mathrm{~cm}$ )to study muddy water mixtures. Test results show that the higher the content of fine particles (especially clay) in dredger fill, the longer the process of self weight deposition, the ratio of pore to sediment is larger, and the pore ratio of silty soil after consolidation is 1 2, while silty clay is between 2 6. Xianwei Zhang ${ }^{[5]}$ took the dredger fill mud in Tianjin Binhai New Area as the object of study, and studies the rule of mud self weight settlement and consolidation of initial water content 200 2000\%. The sedimentation types of dredger fill mud in Tianjin are mainly sedimentary subsidence and consolidation subsidence. The sedimentation process is divided into flocculation stage, hindered settlement stage and self consolidation stage. In the process of settlement, the consolidation settlement gradually changes with the decrease of water content. When the initial moisture content is less than $400 \%$, consolidation settlement occurs, and sedimentation occurs when the initial water content is greater than $400 \%$. 
Guizhong $\mathrm{Xu}^{[6]}$ used a diameter of $6.5 \mathrm{~cm} 1000 \mathrm{ml}$ cylinder to test, the soil moisture content of Baima Lake is 397 1991\%, and the water content of soil sample in Wenzhou is 325\% 1921\%. The soil moisture content of the soil samples in the gateway and the soil samples in is $255 \%$ 2120\%, and the water content of the soil samples in Zhangjiagang is $64.1 \sim 455.5 \%$. The moisture content of soil formation (When the mud enters the consolidation state, the water content is the moisture content of soil formation) is related to the liquid limit of soil sample, the clay soil is about 9 times of the liquid limit, and the silty soil is about 3 times of the liquid limit. Nan Zhang ${ }^{[7]}$ uses a settlement column with a height of $0.8 \mathrm{~m}$ and an inner diameter of $0.1 \mathrm{~m}$. The silt is dredged from the Yixing iron ore yard in Jiangsu, and the initial water content is $1103 \%$. During the settlement of dredger fill mud, the settlement rate of particles will appear mud water interface, floc settlement and floc compression settlement interface and self weight consolidation interface. Ming Zhang ${ }^{[8]}$ is based on the boundary void ratio as the dividing line between the deposition and the consolidation of gravity in the process of silt deposition, and considering the deformation after gravity deposition. Shaolin Le, Wei Bai, Mingjiang Wu researched the dredger fill. Large scale settlement column test for mixed sand and dredger fill is carried out, The test results show that the sediment and sediment distribution and the distribution of particles are closely related to the initial sand content and initial water content. The settlement time curve can be divided into 3 stages: rapid subsidence, slow subsidence, and slow settlement consolidation. The second stage shows obvious nonlinear characteristics. With the decrease of initial water content, the 3 stages of sedimentation time curve and nonlinear characteristics are not obvious.

In this paper, mixed soil of clay soil and sand are taken as the object, and the settlement consolidation law of dredger fill of clay soil mixing sand is studied by the settlement column test.

\section{TEST METHOD}

The clay mixed sand samples used in the test are configured. Clay soil is taken from the site near Baoding, East Lake. The plastic limit is $22.6 \%$, the liquid limit is $41.7 \%$, the water content is $45.2 \%$, and the density is $1.822 \mathrm{~g} / \mathrm{cm}^{3}$.

The gradation of sand using in the test: Particle size $\mathrm{d}>0.5 \mathrm{~mm}$, particle content $2 \%, 0.25 \mathrm{~mm} \sim 0.5 \mathrm{~mm}$ accounted for $84.1 \%$, particle size $0.075 \mathrm{~mm} \sim 0.25 \mathrm{~mm}$ accounted for $12.01 \%$, particle size $<0.075 \mathrm{~mm}$ accounted for $1.9 \%$. According to current regulations ${ }^{[10]}$ belongs to medium sand.

The water contents were $80 \%, 100 \%$ and $200 \%$ respectively. Clay sand mixed soil with sand-mud ratios of $0,5 \%$, $10 \%, 15 \%, 20 \%$ and $25 \%$, respectively, as in the settlement column. The settlement column size is $100 \times 500 \mathrm{~mm}$. The consolidated height of liquid between clayey soil and sand fill is between 400 430mm, and the self weight consolidation test is carried out.

\section{ANALYSIS OF TEST RESULTS}

\subsection{Settlement curve}

Fig. 1 shows the variation of the settlement with time when the sand content ratio is between $0 \sim 25 \%$ and when the water content is $80 \%, 100 \%$ and $200 \%$ respectively. Fig. 2 is the test result of the reference [9]. When the water content is $100 \%$, $200 \%$ and $300 \%$, the sand content ratio varies with time at 10\%, 20\% and 30\% respectively. From Fig. 1 and Fig. 2, the main factor affecting the settlement of clay soil and sand mixed dredger fill is the initial water content. With the increase of initial water content, mud sinking faster, sedimentation value increased, the consolidation time decreased. The completion time of consolidation decreases obviously with the increase of initial moisture content. The consolidation stability time is obviously lower than the stability time of the reference [9], the main reason is that the settlement column size of the literature [9] is 2 times of the test, the diameter is $200 \mathrm{~mm}$, the height is $1300 \mathrm{~mm}$.

The results show that when the initial water content is $200 \%, 100 \%, 80 \%$ and the sand content ratio is between $0 \sim 25 \%$, the settlement values are 18.66 26.11\%, 26.67 33.60\% and 50.9 55.35\% respectively. The results in the reference [9], when the moisture content is $100 \%$, the sand-mud ratio is $20 \%$ and $30 \%$, stable subsidence values were $29.09 \%$ and $30.50 \%$ respectively; when the initial water content is $200 \%$, the sand-mud ratio is $10 \%, 20 \%$ and $30 \%$, stable subsidence values were $43.65 \%, 57.12 \%$ and $53.47 \%$. There is little difference between the results and this test. 


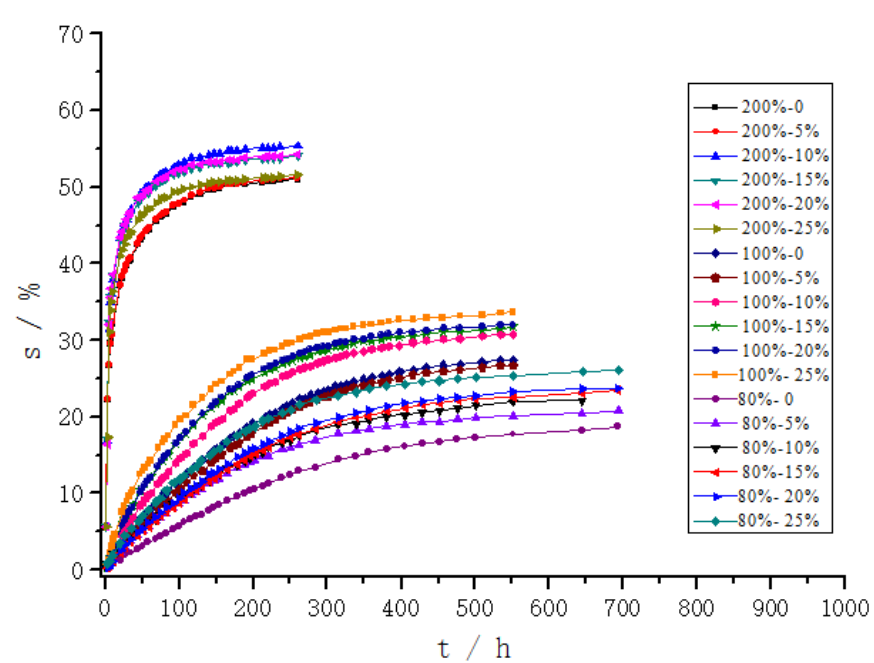

FIG. 1 s-t CURVE OF DIFFERENT WATER CONTENT AND DIFFERENT SAND-MUD RATIO

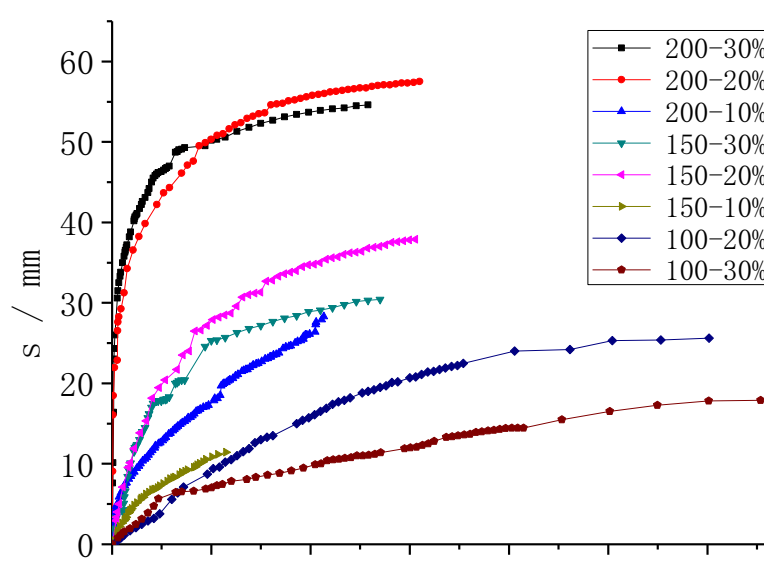

FIG. 2S-t CURVE OF DIFFERENT WATER CONTENT AND DIFFERENT SAND-MUD RATIO(REFERENCE [9])

The s-t curve of dredger fill of clay soil mixing sand is fitted according to the following functions:

$$
S=A_{1} e^{-\frac{t}{t_{1}}}+A_{2} e^{-\frac{t}{t_{2}}}+S_{0}
$$

In the formula, $S$ is the settlement, and $A_{1}, A_{2}, S_{0}, t_{1}, t_{2}$ is the fitting parameter.

The relation in the upper form is $S_{t \rightarrow \infty}=S_{0}$, so $S_{0}$ is the stable value when the settlement consolidation is completed.

Table 1 Table 3 provides the corresponding fitting parameters for different water content and different sand-mud ratio. From table 1 table 3, the fitted function of the time dependent relationship between the sedimentation and the time is nonlinear exponential polynomial, and the correlation coefficients are greater than 0.995 . Therefore, the correlation is good

TABLE 1

FITTING PARAMETERS WITH WATER CONTENT OF $80 \%$

\begin{tabular}{|c|c|c|c|c|c|c|}
\hline $\begin{array}{c}\text { Sand-mud } \\
\text { ratio }\end{array}$ & $A_{1}$ & $t_{1}$ & $A_{2}$ & $t_{2}$ & $S_{0}$ & $\begin{array}{c}\text { Correlation } \\
\text { Coefficient }\end{array}$ \\
\hline 0 & -10.5887 & 280.0482 & -10.5887 & 280.0464 & 20.87022 & 0.99795 \\
\hline 5 & -10.6600 & 187.1941 & -10.6600 & 187.1939 & 21.42909 & 0.99894 \\
\hline 10 & -11.5269 & 203.2542 & -11.5269 & 203.2550 & 23.45973 & 0.99854 \\
\hline 15 & -12.5249 & 214.3406 & -12.5249 & 214.3402 & 24.77805 & 0.99891 \\
\hline 20 & -12.5452 & 198.5618 & -12.5452 & 198.5620 & 24.88548 & 0.99900 \\
\hline 25 & -13.1941 & 169.3581 & -13.1941 & 169.3583 & 26.67707 & 0.99915 \\
\hline
\end{tabular}

TABLE 2

FITTING PARAMETERS WITH WATER CONTENT OF 100\%

\begin{tabular}{|c|c|c|c|c|c|c|}
\hline $\begin{array}{c}\text { Sand-mud } \\
\text { ratio }\end{array}$ & $A_{1}$ & $t_{1}$ & $A_{2}$ & $t_{2}$ & $S_{0}$ & $\begin{array}{c}\text { Correlation } \\
\text { Coefficient }\end{array}$ \\
\hline 0 & -14.99742 & 193.0823 & -14.9974 & 193.0825 & 30.09272 & 0.99947 \\
\hline 5 & -15.3231 & 215.4505 & -15.3231 & 215.4523 & 30.44765 & 0.99867 \\
\hline 10 & -16.9343 & 162.7865 & -16.9343 & 162.787 & 33.89887 & 0.99933 \\
\hline 15 & -31.4496 & 140.3179 & -2.00026 & 10.17136 & 32.77557 & 0.99971 \\
\hline 20 & -16.5151 & 133.7142 & -16.5151 & 133.7142 & 33.23667 & 0.99957 \\
\hline 25 & -30.7086 & 129.2871 & -3.20926 & 12.05774 & 33.28825 & 0.99959 \\
\hline
\end{tabular}


TABLE 3

FITTING PARAMETERS WITH WATER CONTENT OF $200 \%$

\begin{tabular}{|c|c|c|c|c|c|c|}
\hline $\begin{array}{c}\text { Sand-mud } \\
\text { ratio }\end{array}$ & $A_{1}$ & $t_{1}$ & $A_{2}$ & $t_{2}$ & $S_{0}$ & $\begin{array}{c}\text { Correlation } \\
\text { Coefficient }\end{array}$ \\
\hline 0 & -40.13903 & 2.12109 & -21.8216 & 45.16486 & 49.88555 & 0.99737 \\
\hline 5 & -39.98749 & 2.11719 & -21.7335 & 45.13955 & 49.6558 & 0.99738 \\
\hline 10 & -15.89544 & 49.98365 & -44.1232 & 3.62553 & 52.21738 & 0.99519 \\
\hline 15 & -47.19616 & 3.43505 & -14.8783 & 48.20942 & 53.07849 & 0.99867 \\
\hline 20 & -15.08462 & 46.23893 & -46.5062 & 3.49794 & 53.16765 & 0.99933 \\
\hline 25 & -45.05877 & 3.22394 & -15.5957 & 45.59238 & 52.47949 & 0.99971 \\
\hline
\end{tabular}

In the s-t curve, when the settlement curve tends to horizontal, the excess pore water pressure in the slurry is dissipated, and the mud self weight consolidation is completed, indicating the end of the natural settlement. The time required for the end of a natural settlement is called settling time and is expressed by $T_{c} . T_{c}$ is an important reference index for design of yard capacity in blowing and filling project. $T_{c}$ is closely related to initial water content. The settlement consolidation time is defined as settlement consolidation time of $95 \%$, which is used as settling stability time. With the formula (1), it is easy to determine the time at which the settlement consolidation is completed 95\% (as shown in Fig.3).When the initial water content is $200 \%$, the settling time is less affected by sand content than between $82 \sim 98 \mathrm{~h}$; When the initial water content is $100 \%$ and $80 \%$, the consolidation time is related to the sand content. Except for individual points, settling stability time decreases with the increase of sand content, and when the water content is $100 \%$ and $80 \%$, respectively, 650 375h, 845 506h.Compared with the reference [9], 200\% when the initial water content, sand-mud ratio were $10 \%, 20 \%$ and $30 \%$, stable settlement time were $365 \mathrm{~h}, 610 \mathrm{~h}$ and $2920 \mathrm{~h}$ is much higher than the test value, the main reason is 2 times the size of the settlement column close to the test size, drainage distance is 2 times as the test, so the consolidation settlement completion time is far greater than the consolidation time.

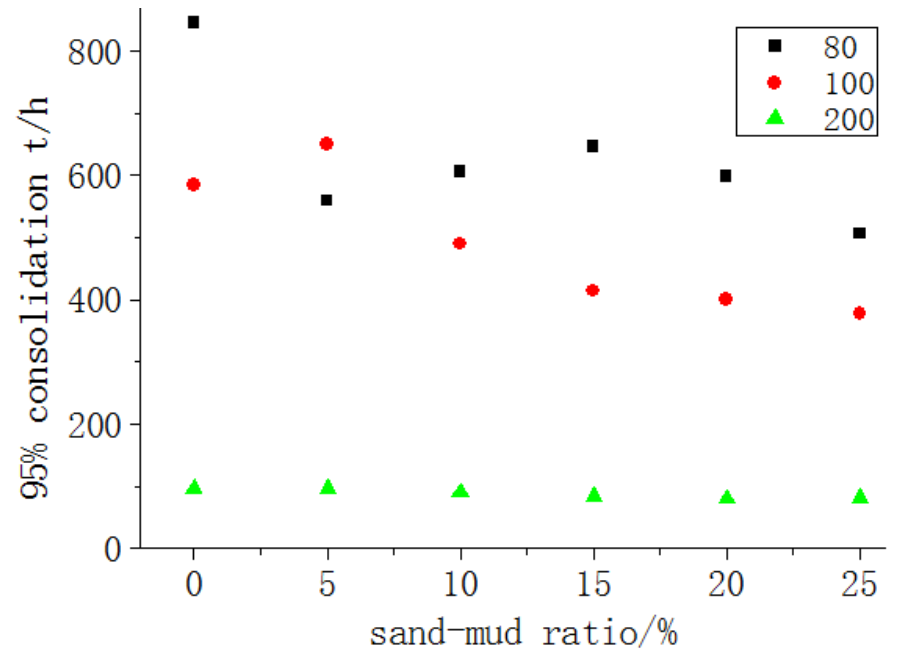

FIG.3 RELATIONSHIP BETWEEN CONSOLIDATION TIME, $w$ AND SAND-MUD RATIO WHEN CONSOLIDATION IS COMPLETED 95\%

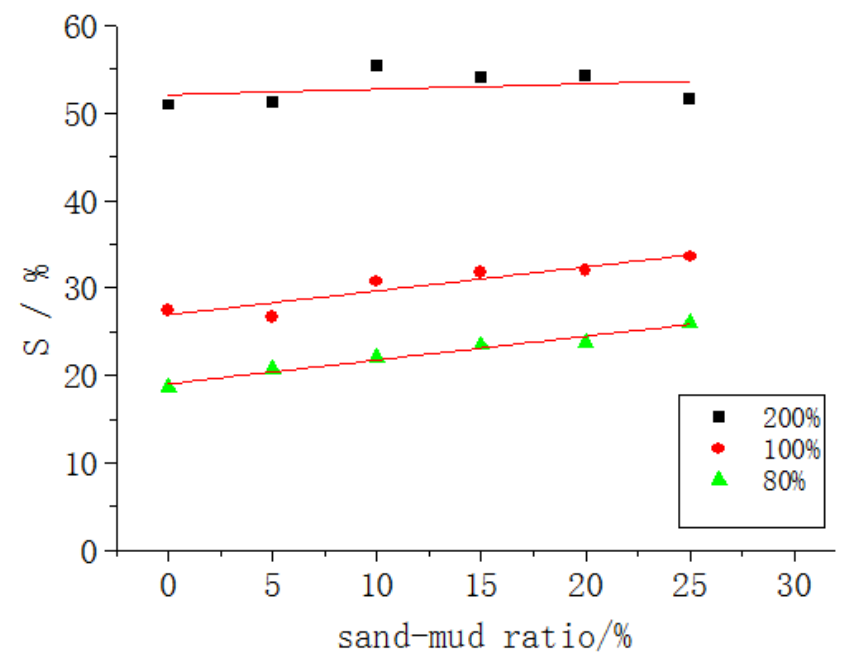

FIG.4 RELATIONSHIP BETWEEN SETTLEMENT STABILITY VALUE AND SAND-MUD RATIO UNDER DIFFERENT WATER CONTENT

Fig. 4 is the change of settlement stability value with sand-mud ratio under different water content. As shown in Fig. 4 , the settlement stability value increases linearly with the increase of sand content ratio. Linear equation is for: 


$$
\begin{array}{ll}
S_{c}=52.104+0.06218 \alpha & \left(w_{0}=200 \%\right) \\
S_{c}=26.95+0.27358 \alpha & \left(w_{0}=100 \%\right) \\
S_{c}=19.07+0.27162 \alpha & \left(w_{0}=80 \%\right)
\end{array}
$$

In the formula, $S_{c}$ is the stable settlement value, and $\alpha$ is sand-mud ratio between $0 \sim 25 \%$.

\subsection{Settlement rate curve}

Fig.5 Fig.7 is the curve of settlement rate versus time. As shown in Fig. 3 Fig. 5, at the initial stage of settlement, the settlement rate is greatly affected by the initial water content. When the water content is $200 \%$, the initial settlement rate is about $35 \mathrm{~mm}$, and the settlement rate is less than 0.007 when the settlement is $95 \%$; When the water content is $100 \%$ and $80 \%$, the maximum velocity is about 2 and 1.5 respectively. When the settlement is $95 \%$, the rates are less than 0.002 and 0.004 respectively.

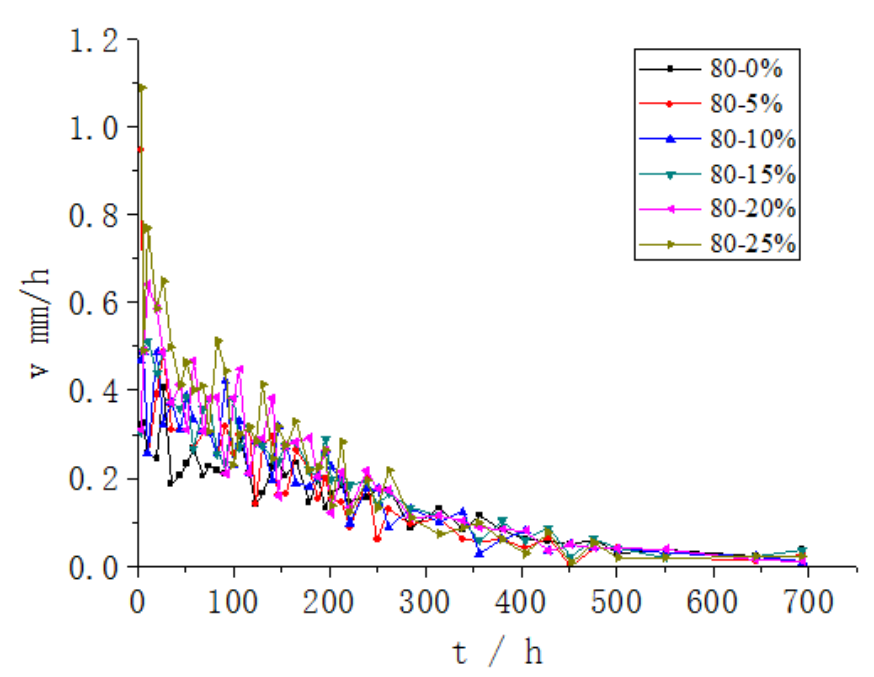

FIG. 5: v-t CURVE OF DIFFERENT SAND-MUD RATIO $w=80 \%$

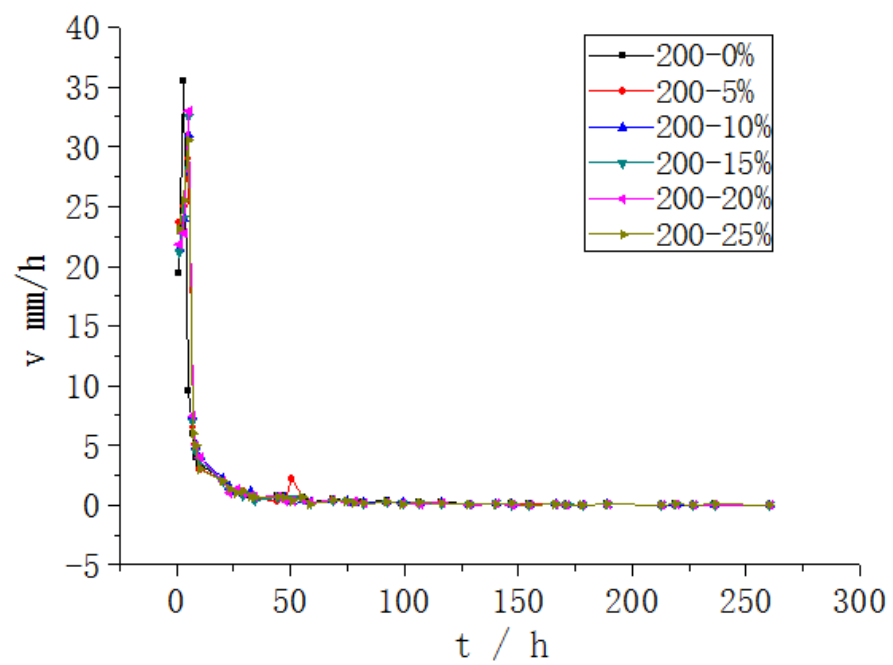

FIG. 7 v-t CURVE OF DIFFERENT SAND-MUD RATIO $w=200 \%$

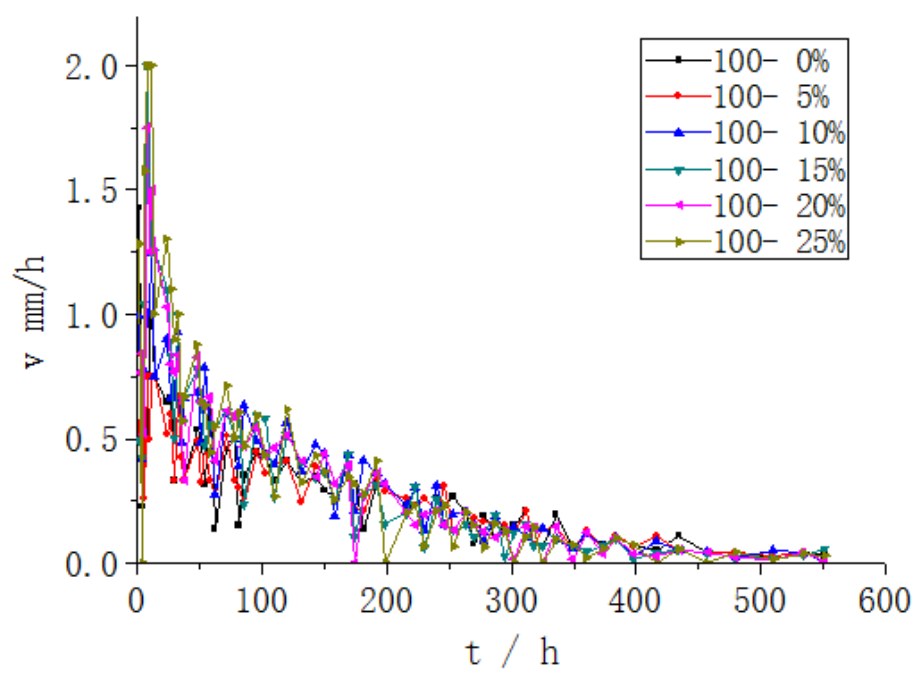

FIG. 6 v-t CURVE OF DIFFERENT SAND-MUD RATIO $w=100 \%$

\subsection{Log curve of settling time}

Fig. 8 is the change curve of settlement with time logarithm. Fig.9 is the change curve of settlement with time logarithm in reference [9]. As can be seen from Fig.8 and Fig.9, the curve is basically divided into three stages: the straight line segment, the upper concave line segment and the lower concave line segment. At the begin, the curve begins is linear, and with the 
increase of the initial water content, the slope of the straight line segment increases gradually; The upper concave curve gradually decreases with the increase of water content; The concave curve section gradually changes to the curve type, then the slope of the settlement curve decreases and finally tends to the horizontal. In this experiment, when the water content is $200 \%$,the upper concave line is close to the straight line, while in the reference [9], when the water content is $200 \%$ and the sand-mud ratio is $20 \%$ and $30 \%$, the upper concave line is close to the straight line, and when the sand-mud ratio is $10 \%$, the upper concave curve is a curve.

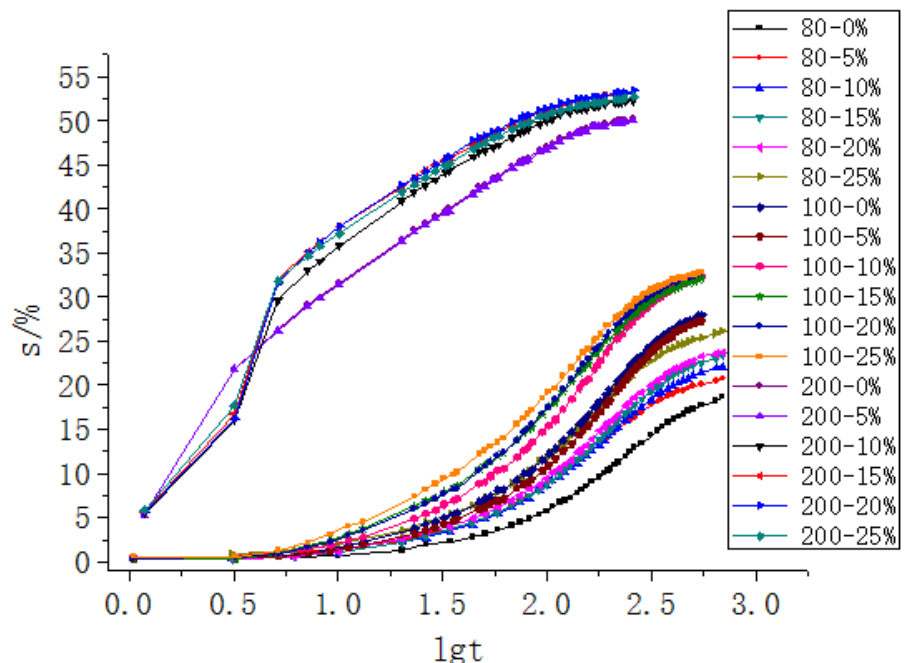

FIG. 8 s-logtcurve WITH DIFFERENT $w$ AND DIFFERENT SAND-MUD RATIO

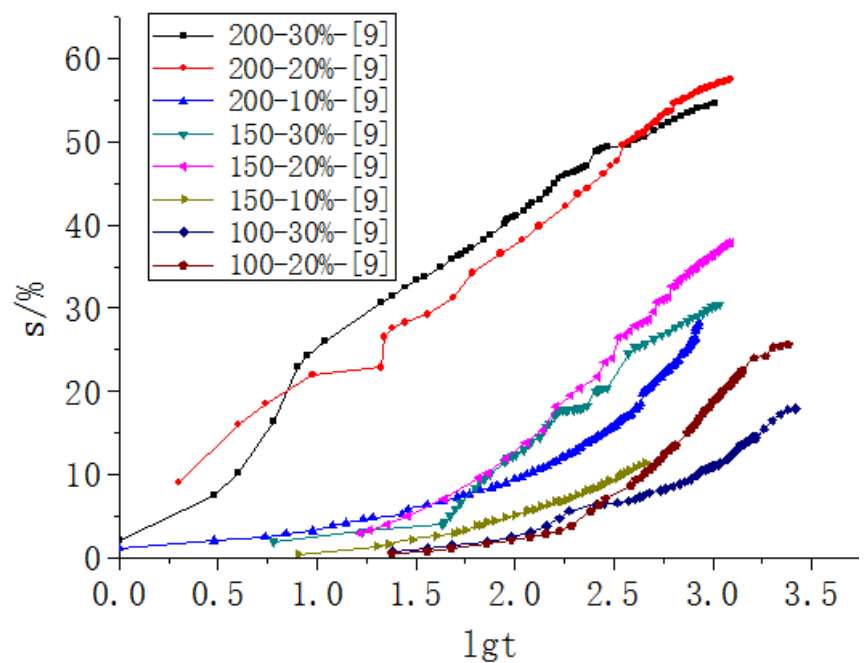

FIG. 9 s-logtcurve WITH DIFFERENT $w$ AND DIFFERENT SAND-MUD RATIO(REFERENCE [9])

\subsection{Test index of settlement consolidation is completed}

Fig.10 Fig.12 show the variation of density and dry density, void ratio and water content with sand content after completion of settlement consolidation. When the water content were $80 \%, 100 \%, 200 \%$ and the sand-mud ratio is between $0 \sim 25 \%$, the density increased along with increasing sand-mud ratio. After completion of the test, $80 \%$ water content, soil density changes in the range of 1.722 1.8, the dry density changes in the range of $1.105 \sim 1.149 ; 100 \%$ water content, soil density changes in the range of 1.697 1.743, the dry density changes in the range of 1.058 1.114; $200 \%$ water content, soil density changes in the range of 1.859 1.768, the dry density changes in the range of 1.174 1.201.After self consolidation, the void ratio of soil samples is between 1.2 1.6 and the moisture content is between $45 \sim 60 \%$, and the water content is higher than that of the initial clay soil $(45.2 \%)$.

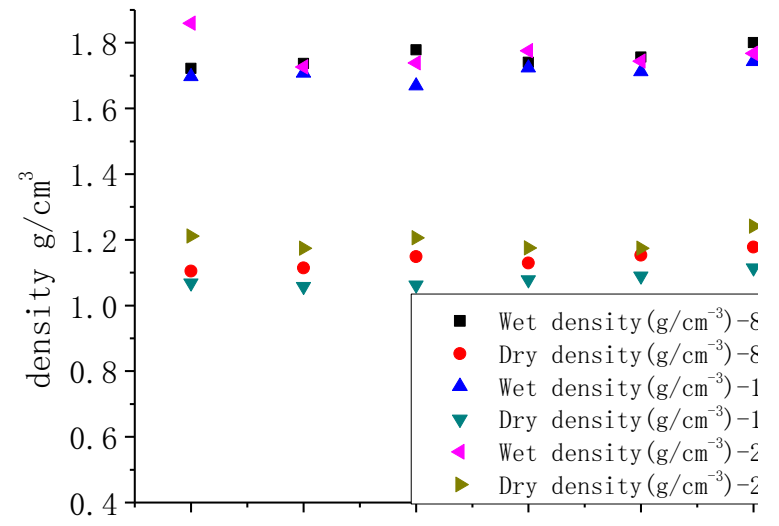

FIG. 10 RELATION BETWEEN DENSITY AND SANDMUD RATIO AFTER CONSOLIDATION OF SELF WEIGHT SETTLEMENT

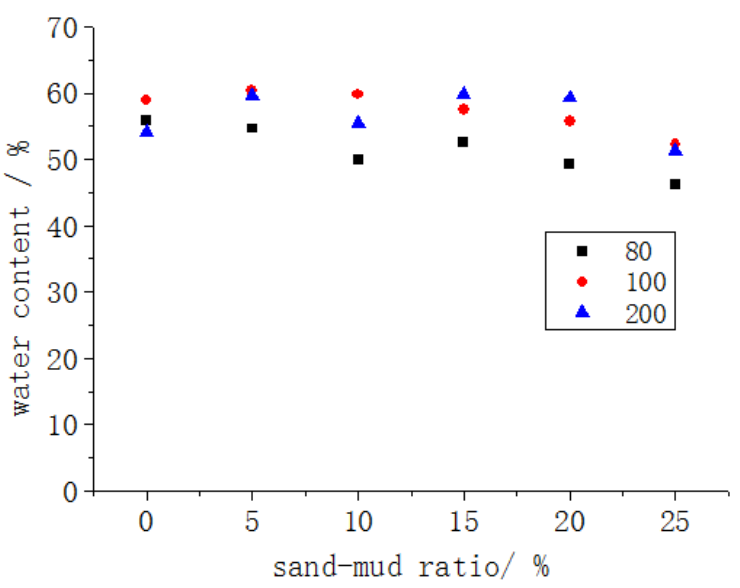

Fig. 11 RELATION BETWEEN W AND SAND-MUD RATIO AFTER CONSOLIDATION OF SELF WEIGHT SETTLEMENT 


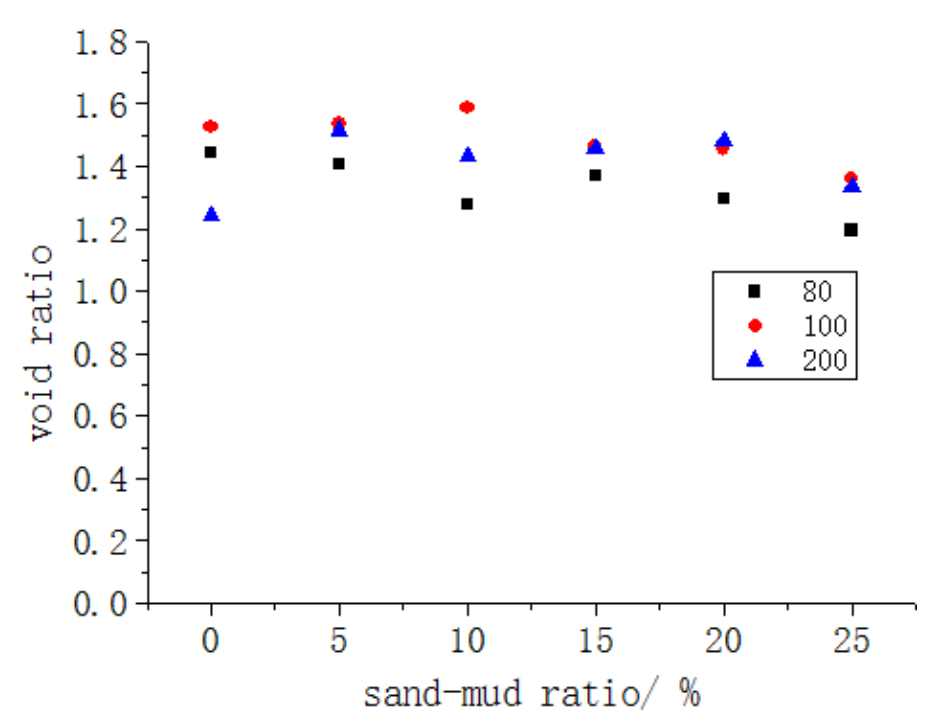

FIG. 12 RELATIONSHIP BETWEEN VOID RATIO AND SAND-MUD RATIO

\section{CONCLUSION}

1) The primary factor affecting the settlement of dredger fill of clay soil mixing sand is the initial water content. With the increase of initial water content, the settlement speed of slurry interface is faster, the settlement value increases, and the time of completion of consolidation decreases. The completion time of consolidation decreases obviously with the increase of initial water content. Settlement column size is also one of the major factors of settling stability time, as the settlement column size and drainage distance increase, the consolidation time increases.

2) The settlement curve of mixed sand and clay filled soil conforms to the relation of $S=A_{1} e^{-\frac{t}{t_{1}}}+A_{2} e^{-\frac{t}{t_{2}}}+S_{0}$. In the formula, $S_{0}$ is the stable settlement. According to the formula, the consolidation stability time and the consolidation settlement amount can be determined according to the percentage of completion settlement consolidation. Under the condition of certain water content, the settlement is basically linear with the sand content ratio.

3) The logarithmic time curve of consolidation settlement is basically divided into three stages: straight line section, the upper concave section and the lower concave line segment are formed. At the begin, the curve begins is linear, and with the increase of the initial water content, the slope of the straight line segment increases gradually; With the increase of water content, the upward trend of the concave curve decreases gradually, and when the initial water content reaches a certain value, the upper concave curve becomes a straight line; The lower concave curve section gradually changes to the curve type, then the slope of the settlement curve decreases and finally tends to the horizontal. In this test, when the water content is $200 \%$, the upper concave line is close to the straight line, while in the reference [9], when the water content is $200 \%$ and the sand-mud ratio is $20 \%$ and $30 \%$, the concave line is close to the straight line.

\section{REFERENCES}

[1] Stokes G G. On the effect of the internet friction of fluids on the motion of pendulums[J]. Trans. Combridge Philo. Soc., 1851.9(2) : 89-106.

[2] IMAI G. Experimental studies on sedimentation mechanism and sediment formation of clay materials[J].Soils and Foundations, 1981,21(1):7-20.

[3] IMAI G. Settling behavior of clay suspension[J]. Soils and Foundations, 1980,20(2):61-77.

[4] Liangtong Zhan, Jun Tong, Jie Xu.Laboratory study on self-weight sedimentation and consolidation behaviors of hydraulic-dredged mud[J].SHUILIXUEBAO, 2008,39(2):201-206.

[5] Guizhong Xu, Feng Ji, Jiaxing Weng.Sedimentation Behavior of Dredged Slurry at High Water Contents[J].Journal of Civil Engineering and Management,2012,29(3):22-28.

[6] Nan Zhang, Wei Zhu, Liang Wang. Study of sedimentation and consolidation of soil particles in dredged slurry[J].Rock and Soil Mechanics,2013,34(6):1682-1688. 
[7] Ming Zhang, Guonan Liu, Youming Zhao.Study on Self Weight Consolidation Behaviors of Dredged Fill[J].CHINA RAILWAY SCIENCE,2013,34(5):15-21.

[8] Xianwei Zhang, Aiwu Zhang, Lingwei Kong.Self-weight sedimentation and consolidation characteristics ofhydraulic-dredged slurry in Tianjin Binhai District[J].Chinese Journal of Geotechnical Engineering,2016,38(5):769-777.

[9] Shaolin Le, Wei Bai, Mingjiang Wu.Effect of Sand-mud Ratio on Heterogeneous Dredger Fill Soil and Particle Distribution under Deposited Deadweight[J].Rock and Soil Mechanics,2017:38(S1):233-240.

[10] Ministry of Construction of the PRC, GB 50021-2001. Code for investigation of geotechnical engineering[S].Beijing: China Architecture and Building Press, 2009. 